\title{
A New Modeling of the Junction Metal Semiconductor for Rectenna System
}

\author{
Abdelhak Hamid allah ${ }^{1}$, Ahmed Errkik ${ }^{2}$, Jamal Zbitou ${ }^{3}$,Larbi El Abdellaoui ${ }^{4}$,Abdelali \\ Tajamouati ${ }^{5}$,Mohamed Latrach ${ }^{6}$ \\ \{abdelhakhamidallah@gmail.com ${ }^{1}$, ahmed.errkik@uhp.ac.ma², zbitouj@gmail.com ${ }^{3}$ \} \\ LMEET Laboratory FST of Settat Hassan 1st University Morocco 1,2,3,4,5, Microwave group ESEO \\ Angers France ${ }^{6}$
}

\begin{abstract}
This article presents a new design and optimization of the junction MetalSemiconductor $(\mathrm{Au} / \mathrm{n}-\mathrm{GaAs})$ optimized in performances. This study has as objective the design of a new Schottky diode which is dedicated to the design of new RF-DC rectifiers in order to increase and to improve the performances of rectenna, and the microwave applications in general. The modelling is based initially on the determination of the breakdown voltage and then the calculation and optimization of all the principal parameters of the Schottky diode. For validation, the proposed study is compared with the commercial diodes.
\end{abstract}

Keywords: Junction Metal-Semiconductor, GaAs Schottky Diode, Schottky Barrier, Rectenna, Diode Modeling .

\section{Introduction}

The semiconductor devices are in the foreground of modern technology. Each day, the powerful semiconductor devices are developed and contribute to the spectacular results got in various spheres of the scientific and technology activity. The structures metal semiconductors (Schottky diode) are components widely used in microelectronics and microwaves applications for the manufacturing of integrated circuits on one hand and as a basic competent in commutation, on the other hand. In this context the Schottky diode is the most used element for the manufacturing and the design of the rectifier rectenna. Among the semiconductor with direct band gap and higher electronic mobility, the gallium arsenide (GaAs) [1], [2]. It's a semiconductor which starts to become a serious competitor for silicon ( $\mathrm{Si}$ ). Moreover, it can easily be doped $\mathrm{n}$ or $\mathrm{p}$, and its operating temperature reaches at least $600^{\circ} \mathrm{C}-700^{\circ} \mathrm{C} \mathrm{[3],} \mathrm{[4].}$ Indeed, the characteristic of the metal-semiconductor junction is nonlinear when it functions at high powers and its performances on the conversion operation are very limited. The objective is the design of a diode $\mathrm{Au} / \mathrm{n}$-GaAs Zero biased, which works with low, high power levels and having a good detection sensitivity and good performance in terms of rectifying operation. The study begins with the fixation of a breakdown voltage which is suitable for high levels of power, then the optimization of the parameters and properties of the diode using the methodology detailed in Figure 1 and in the following section. 


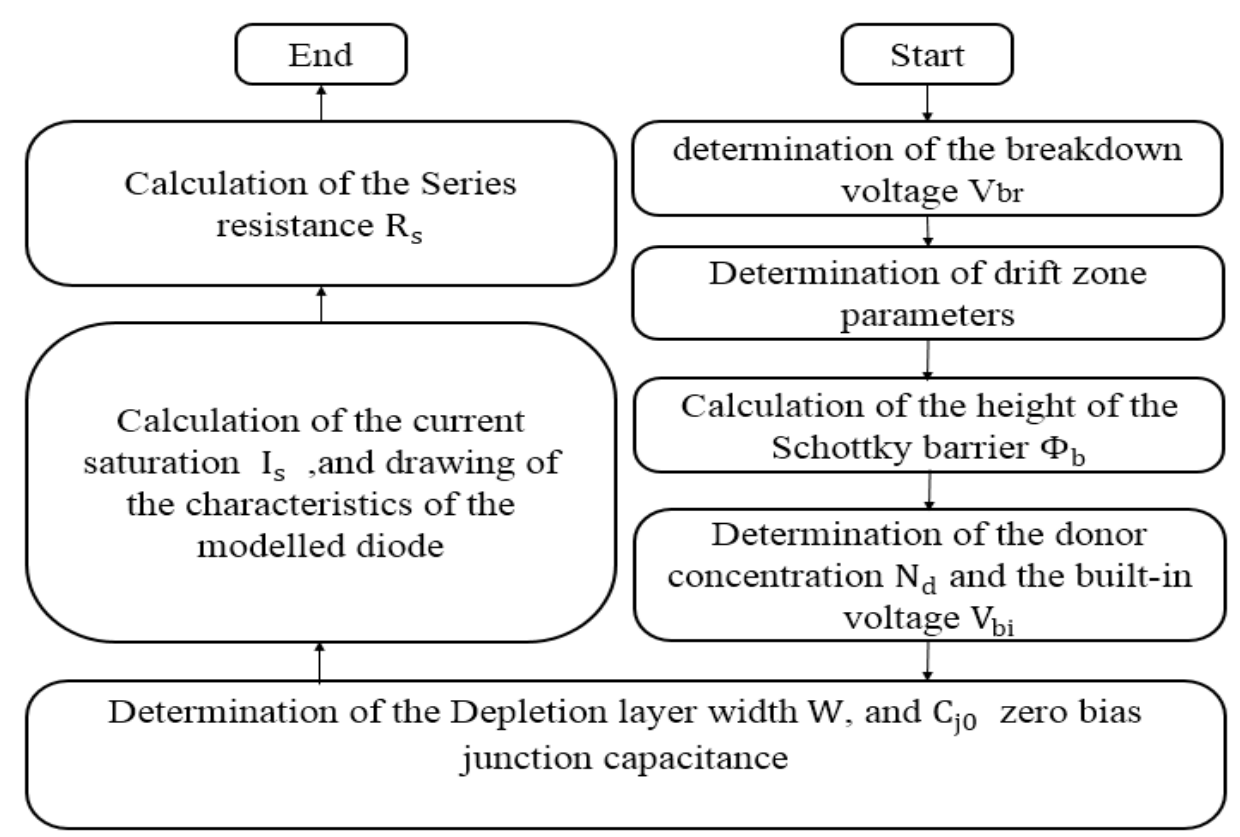

Fig. 1. Diagram of the calculation and modeling carried out in Matlab.

\section{Modeling and optimized parameters}

According to [5] a study conducted to evaluate the conversion efficiency of a rectenna. The breakdown voltage $V_{b r}$, the zero-biased junction capacitance $C_{j 0}$ and the series resistance $R_{s}$ Are the principal elements which determine the efficiency of RF-DC conversion for a rectenna and the global performances of commercial diodes, those parameters are related to the properties of selected materials [1]. In addition, the maximum power of a rectenna or the critical input power where the output voltage DC becomes limited, is given by the following equation $P_{R F}=\frac{V_{b r}{ }^{2}}{4 R_{L}}$. Therefore, this power is limited by the value of the breakdown voltage thus also limiting the efficiency and the performance of the rectenna. For this reason, we decided to begin this modeling with the determination of the breakdown voltage $V_{b r}$ and then to extract and modeled all principal parameters of the diode.

\subsection{Determination of drift region parameters}

The breakdown voltage we had chosen for this study is $V_{b r}=100 \mathrm{~V}$. According to [6] the relationships between the breakdown voltage, the drift region width, and drift region concentration or (drift region doping) are expressed by the equations (1) and (2). 


$$
\begin{aligned}
& \mathrm{N}_{\mathrm{d}}^{+}=2 \times 10^{18} \times\left(\mathrm{V}_{\mathrm{br}}{ }^{-4 / 3}\right) \mathrm{cm}^{-3} \\
& \mathrm{~W}_{\mathrm{D}}=2.67 \times 10^{10} \times\left(\mathrm{N}_{\mathrm{d}}^{+}\right)^{-7 / 8} \mathrm{~cm}
\end{aligned}
$$

With $\mathrm{N}_{\mathrm{d}}{ }^{+}$is the drift region concentration and $W_{D}$ is the drift region width, to see Figure 2.

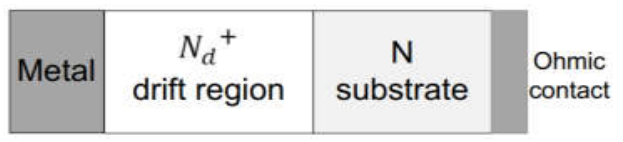

Fig. 2. Structure metal semiconductor.

The value of the breakdown voltage decreases notably when the concentration increases, and conversely for the width the voltage increases. The variation between dimensions of the drift region and the breakdown voltage is traced in Figure 3.a and Figure 3.b.

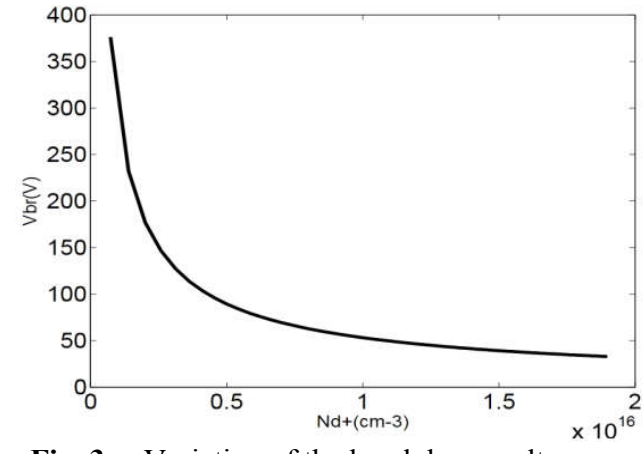

Fig. 3.a. Variation of the breakdown voltage $\mathrm{V}_{\mathrm{br}}$ vs. Drift region concentration $\mathrm{N}_{\mathrm{d}}{ }^{+}$.

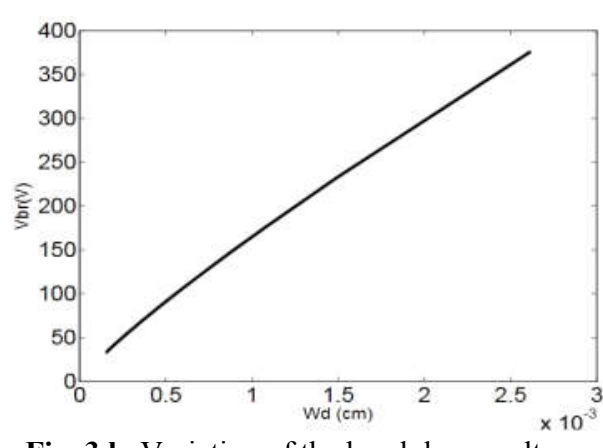

Fig. 3.b. Variation of the breakdown voltage $\mathrm{V}_{\mathrm{br}}$ vs. Drift region concentration $\mathrm{N}_{\mathrm{d}}{ }^{+}$.

\subsection{Schottky barrier height $\Phi_{\mathrm{b}}$}

The barrier height can be expressed as (3)

$$
\Phi_{\mathrm{b}}=\Phi_{\mathrm{m}}-\mathrm{X}_{\mathrm{s}}
$$

With $\Phi_{\mathrm{m}}$ work function of the metal (gold for our study), and $\mathrm{X}_{\mathrm{s}}$ is the electronic affinity of semiconductor (GaAs).

For our study, the work function of $\mathrm{Au}$ is $\Phi_{\mathrm{m}}=5.06 \mathrm{eV}$ [7],[8], and the electronic affinity of GaAs is $X_{s}=4.07 \mathrm{eV}[1]$, therefore the barrier height is $\Phi_{b}=0.98 \mathrm{eV}$. Figure 4 is traced using the equation $\Phi_{\mathrm{b}}=0.12 \Phi_{\mathrm{m}}+0.37$ [7], representing the variation between a barrier height and a work function. 


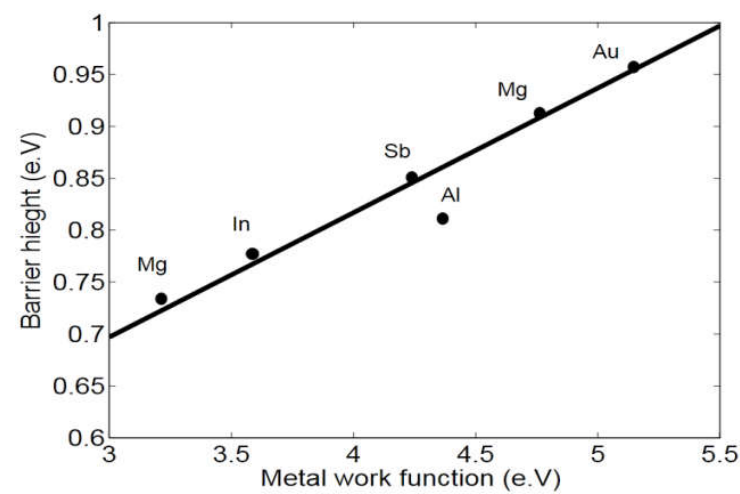

Fig. 4. Barrier height values for different metals plotted against the metal work function.

\subsection{Donor concentration $N_{d}$ and the built-in voltage $V_{b i}$}

To calculate the built-in voltage, we substitute the equations (3) and (5) into (4), the curve that models the evolution of $V_{b i}$ is given in the Figure 5.a. Regarding the breakdown voltage $V_{b r}$, we replace the relations (4), (5) and (6) in the equation (7). The curve in Figure 5.b shows the variation between the donor concentration $N_{d}$ and voltage $V_{b r}$, we note we have a high donor concentration the breakdown voltage decreases [1], [9], [10].

$$
\begin{aligned}
& \mathrm{V}_{\mathrm{bi}}=\Phi_{\mathrm{b}}-\frac{\mathrm{KT}}{\mathrm{q}} \times \ln \left(\frac{\mathrm{N}_{\mathrm{c}}}{\mathrm{N}_{\mathrm{d}}}\right) \\
& \mathrm{N}_{\mathrm{c}}=4.7 \times 10^{17} \times\left(\frac{\mathrm{T}}{300}\right)^{3 / 2} \\
& \mathrm{E}_{\mathrm{cr}}=\frac{2.49 \times 10^{6}}{1-0.25 \times \log \left(\mathrm{N}_{\mathrm{d}} \times 10^{-16}\right)} \\
& \mathrm{V}_{\mathrm{br}}=\frac{\varepsilon_{\mathrm{s}} \times\left(\mathrm{E}_{\mathrm{cr}}\right)^{2}}{2 \mathrm{q} \mathrm{N}_{\mathrm{d}}-\mathrm{V}_{\mathrm{bi}}}
\end{aligned}
$$

Where $\mathrm{V}_{\mathrm{bi}}$ is the built-in voltage and, $\mathrm{N}_{\mathrm{c}}$ the density of states at the conduction band edge, $\mathrm{E}_{\mathrm{cr}}$ is the critical electric field, $\varepsilon_{\mathrm{s}}$ is the permittivity of the semiconductor.

The donor concentration and the built-in voltage we got for $\mathrm{V}_{\mathrm{br}}=100 \mathrm{~V}$, Are $\mathrm{N}_{\mathrm{d}}=$ $5 \times 10^{22} \mathrm{~m}^{-3}$, and $\mathrm{V}_{\mathrm{bi}}=0.99 \mathrm{~V}$. 


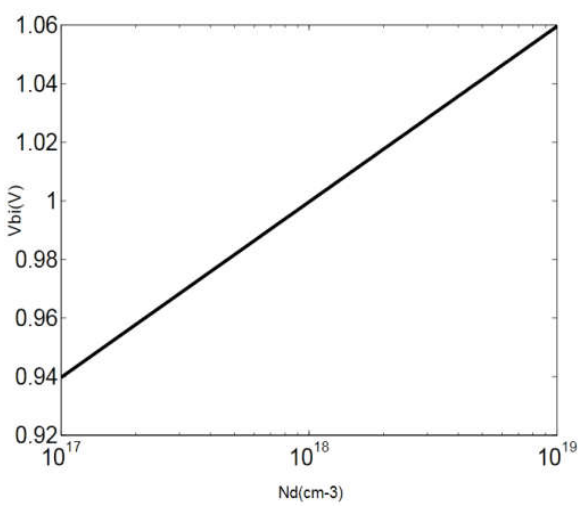

Fig. 5.a Variation of the built-in voltage $V_{b i}$ vs.Donor concentration $\mathrm{N}_{\mathrm{d}}$.

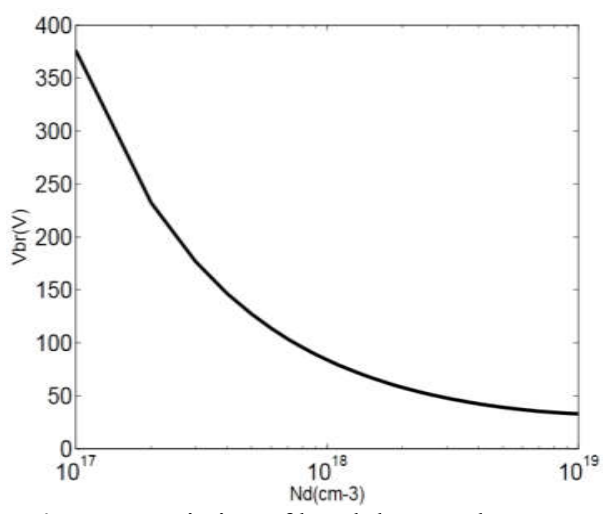

Fig. 5.b Variation of breakdown voltage $\mathrm{V}_{\mathrm{br}}$ vs. Donor concentration $\mathrm{N}_{\mathrm{d}}$

\subsection{Depletion layer width $\mathrm{W}$, and $\mathrm{C}_{\mathbf{j} 0}$ zero bias junction capacitance}

The equation to calculate $W$ is given in the following form (8).

$$
\mathrm{W}=\sqrt{\frac{2 \varepsilon_{\mathrm{s}}}{\mathrm{qN}}\left(\mathrm{V}_{\mathrm{bi}}-\mathrm{V}-\mathrm{kT} / \mathrm{q}\right)}
$$

Where $\mathrm{V}$ is the applied bias, $\mathrm{q}$ the elictronic charge, $\mathrm{T}$ is the temperature $(\mathrm{K})$, with $\mathrm{kT} / \mathrm{q} \approx$ $26 \mathrm{mV}$ for $\mathrm{T}=25^{\circ} \mathrm{C}$.?

The results of the variation of depletion layer width $W$ versus donor concentration and the applied bias are given within the Figure 6. The condition to respect between depletion region width $\mathrm{W}$ and diode thickness $\mathrm{d}$ is defined by $\mathrm{W}<d$. The presence of the depletion region generates a static capacity $C_{j 0}$ or (zero bias junction capacitance) is defined by the relation (9)

$$
C_{j 0}=\sqrt{\frac{q \varepsilon_{s} N_{d} S^{2}}{2 V_{b i}}}
$$

\subsection{The saturation current current $I_{s},(I-V)$ characteristics of the modeled diode}

The saturation current is expressed by the equation (10). On the other hand, in the bibliographical support [7] the ideality factor or the emission constant is $n=1.01$ for a metal function work $\Phi_{m}=5.06$. Concerning how to trace the characteristic (I-V-T), we use the Shockley equation (11). The Figure 7 represents the characteristic in forward bias and under linear scale.

$$
I_{S}=S \times A \times T^{2} \times\left[\exp \left(\frac{-q \Phi_{b}}{K T}\right)\right]
$$

With $\mathrm{S}$ the diode area, $A=8.2 \times 10^{4} \mathrm{~A} / \mathrm{m}^{2} \mathrm{~K}^{2}$ the effective Richardson constant $K=38 \times 0.628510^{-4}$ is Boltzmann's constant. 


$$
\mathrm{I}=\mathrm{I}_{\mathrm{s}} \times\left[\exp \left(\frac{\mathrm{qV}}{\mathrm{nKT}}\right)-1\right]
$$

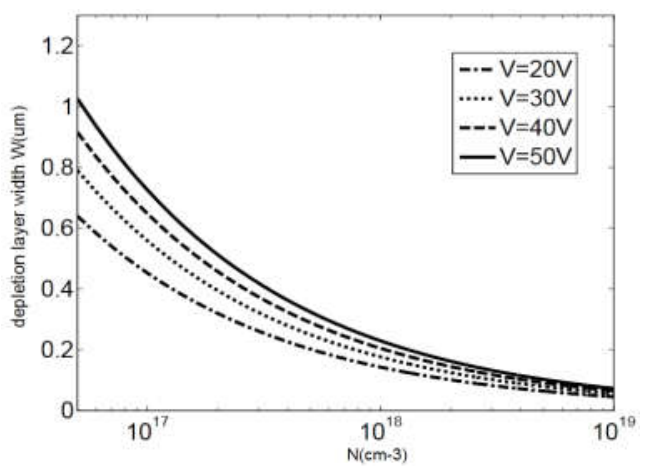

Fig. 6. Depletion layer width $W$ vs. Donor concentration $N_{d}$, and $V$.

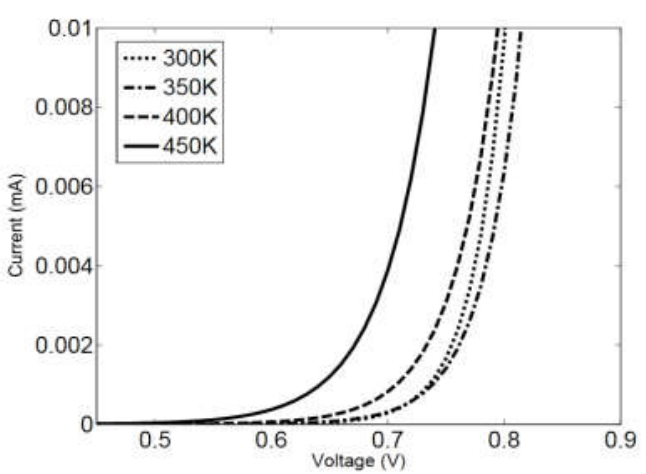

Fig. 7. Linear scale characteristic (I-V-T).

\subsection{Series resistance $\mathbf{R}_{s}$}

The series resistance consists of three resistances $R_{s}=R_{g}+R_{c h}+R_{c}$ where $R_{g}, R_{c h}, R_{c}$ are respectively the junction resistance, the canal resistance, and contact resistance; the three resistances are given by equations (12), (13), (14). After the calculation and the simplification between all equations, the value obtained for the series resistance is $R_{S}=4.6 \Omega$, the variation of the latter is shown in Figure 8 .

$$
\begin{aligned}
& \mathrm{R}_{\mathrm{g}}=\frac{\rho_{\mathrm{m}} \mathrm{D}}{3 \mathrm{tW}} \\
& R c h=\frac{R_{1}\left(R_{2}+R_{3}\right)}{R_{1}+R_{2}+R_{3}} \\
& \left\{\begin{array}{l}
\mathrm{R}_{1}=\frac{1100 \mathrm{~L}}{\mathrm{aN}_{\mathrm{d}}^{0.82} \mathrm{~A}} \\
\mathrm{R}_{2}=\frac{1100 \mathrm{~L}}{\mathrm{a}^{+}\left(\mathrm{N}_{\mathrm{d}}{ }^{+}\right)^{0.82} \mathrm{~A}} \\
\mathrm{R}_{3}=\frac{1100 \mathrm{La}}{\mathrm{N}_{\mathrm{d}}{ }^{0.82} \mathrm{~W}_{\mathrm{D}}}
\end{array}\right. \\
& \mathrm{R}_{\mathrm{c}}=\frac{2100}{\mathrm{P} \times \sqrt{\left(\mathrm{a}^{+}\right)}\left(\mathrm{N}_{\mathrm{d}}{ }^{+}\right)^{0.66}} \\
& \mathrm{P}=2 \mathrm{D}+2 \mathrm{~L}+\mathrm{W}
\end{aligned}
$$

Where $\rho_{m}=2.5 \times 10^{-8} \Omega$. $m$ [4] is the metal resistivity, $W_{D}$ is the drift region width $N_{d}{ }^{+}$is the drift region concentration; all the other parameters are detailed in Figure 9.a and Figure 9.b. 


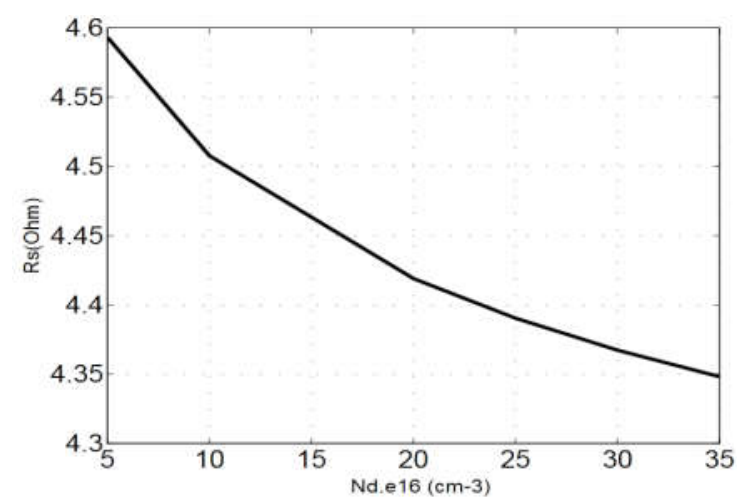

Fig. 8. Variation of series resistance $R_{s}$ vs. Donor concentration $N_{d}$.

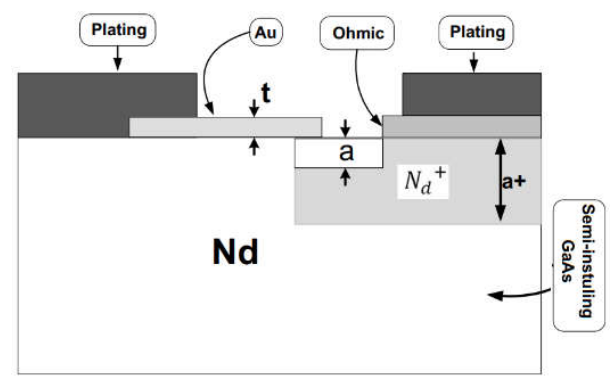

Fig. 9.a.

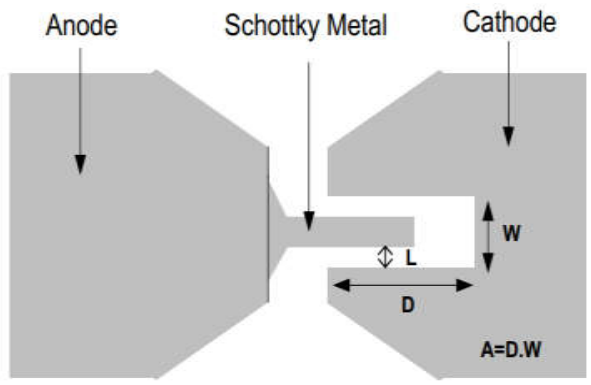

Fig. 9.b.

Fig. 9. $\mathbf{a}$ and $\mathbf{b}$ : the structure of metal-semiconductor detailed.

\subsection{Electron mobility $\mu$ and cutoff frequency $\mathbf{f}_{c}$}

The electron mobility is a concept used in physics to characterize the conducting mediums of the electric current; the gallium arsenide is a semiconductor with higher electronic mobility the maximum electronic mobility for GaAs is approximately $\mu_{\max }=9200 \mathrm{~cm}^{2} /$ $V . s$ at $T=300 \mathrm{~K}$. According to the supports [11], [12], there exist two equations to calculate the electronic mobility (15), (16). The variation of the mobility versus of temperature and donor concentration is presented in Figure 10.

$$
\begin{aligned}
& \mu\left(\mathrm{N}_{\mathrm{d}}\right)=\mu_{\min }+\frac{\mu_{\max }-\mu_{\min }}{1+\left(\mathrm{N}_{\mathrm{d}} / \text { Nref }\right)^{\sigma}} \\
& \mu(\mathrm{T})=\mu(300 \mathrm{~K}) \times\left(\frac{300 \mathrm{~K}}{\mathrm{~T}}\right)^{\alpha}
\end{aligned}
$$

Where $\mu_{\min }, \mu_{\max }$ maximum and minimum mobility $N r e f=1.26 \times 10^{17} \mathrm{~cm}^{-3}[1]$.

Reference doping concentration of GaAs, $\sigma=2.15, \alpha=0.61$ are two constants.

For traditional high-frequency model (Figure 11) of a Schottky diode, the cutoff frequency is given by the equation (17). For this study we find $\mathrm{f}_{\mathrm{c}}=55 \mathrm{GHz}$. 


$$
f_{c}=\frac{1}{2 \pi R_{s} C_{j 0}}
$$
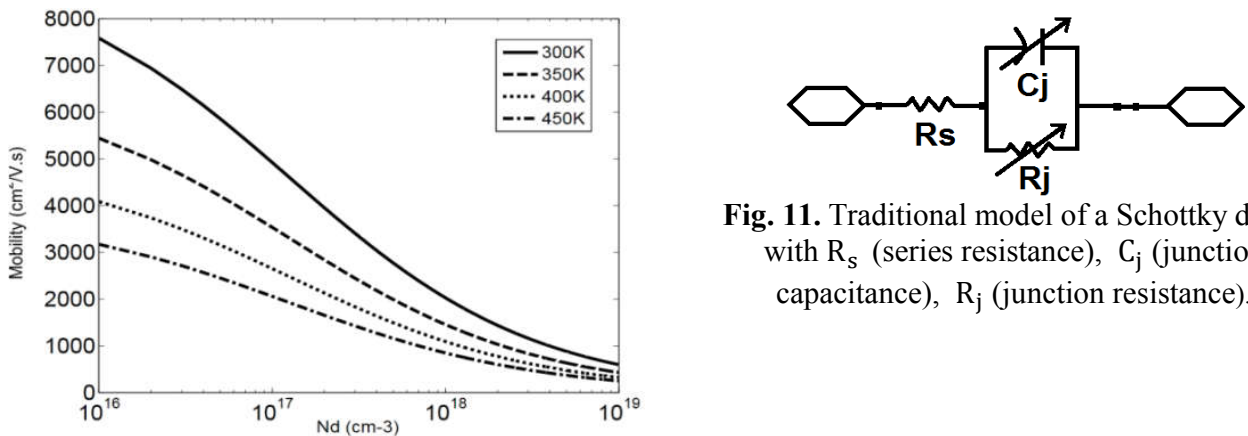

Fig. 11. Traditional model of a Schottky diode with $R_{s}$ (series resistance), $C_{j}$ (junction capacitance), $R_{j}$ (junction resistance).

Fig. 10. Variation of electronic mobility vs. Temperature $\mathrm{T}$ and donor concentration $\mathrm{N}_{\mathrm{d}}$.

Table 1. Comparison between our work and the commercial diode used in other works.

\begin{tabular}{llllll}
\hline Diode & Reference & $\mathrm{V}_{\mathrm{br}}(\mathrm{V})$ & $\mathrm{R}_{\mathrm{S}}(\Omega)$ & $\mathrm{C}_{\mathrm{j} 0}(\mathrm{pF})$ & $\mathrm{I}_{\mathrm{s}}(\mathrm{A})$ \\
\hline BAT-03 & {$[13]$} & 4.6 & 5.0 & 0.1385 & $13.10^{-8}$ \\
KA-BAND & {$[5]$} & 9.0 & 4.85 & 0.13 & $5.24 .10^{-15}$ \\
HSMS-2860 & {$[14]$} & 7.0 & 5.0 & 0.18 & $5.10^{-8}$ \\
HSMS-2820 & {$[15]$} & 15.0 & 6.0 & 0.70 & $2.2 .10^{-8}$ \\
HSMS-2850 & {$[16]$} & 7.0 & 25.0 & 0.18 & $5.0 .10^{-8}$ \\
MA4E1317 & {$[17]$} & 7.0 & 4.0 & 0.02 & - \\
Optimized Diode & This work & 100 & 4.6 & 0.6291 & $6.10^{-15}$ \\
\hline
\end{tabular}

Table 2. Parameters of optimized diode.

\begin{tabular}{llll}
\hline Parameters & Symbol & Value & Unit \\
\hline Breakdown voltage & $\mathrm{V}_{\mathrm{br}}$ & 100 & $\mathrm{~V}$ \\
Series resistance & $\mathrm{R}_{\mathrm{s}}$ & 4.6 & $\Omega$ \\
Zero bias capacitance & $\mathrm{C}_{\mathrm{j} 0}$ & 0.6291 & $\mathrm{pF}$ \\
Saturation current & $\mathrm{I}_{\mathrm{s}}$ & 6 & $\mathrm{fA}$ \\
Built-in voltage & $\mathrm{V}_{\mathrm{bi}}$ & 0.9 & $\mathrm{~V}$ \\
Barrier Height & $\Phi_{\mathrm{b}}$ & 0.98 & $\mathrm{eV}$ \\
Ideality factor & $\mathrm{n}$ & 1.01 & - \\
Cutoff frequency & $\mathrm{f}_{\mathrm{c}}$ & 55 & $\mathrm{GHz}$ \\
\hline
\end{tabular}

\section{Conclusion}

We showed through this study a new modeling of metal semiconductor in $\mathrm{Au} / \mathrm{n}-\mathrm{GaAs}$ technology, in which we calculated all the principal parameters of the junction. Compared to the parameters of commercialized Schottky diode reported in previous work (Table 1), we can conclude that the modeled diode (Table 2) is more performing in several parameters and more 
precisely in the parameters which determine the efficiency of diode, and this was the global goal of our study. Moreover, the proposed study has a several advantages, firstly this study can be used as the guideline for diode conception of a rectifier design, for microwaves applications. Secondly, the study has enabled us to conceive adaptable diodes to our application. Finally, the study allows a high efficiency of microwave applications on which the diodes are the principal element like a rectenna.

\section{References}

[1] S. M. Sze.: Physics of Semiconductor Devices. John Wiley \& sons, New York. London. Sydney. Toronto.1969.

[2] Sheng S. LI.: Semiconductor Physical Electronics. 2nded, Springer, USA, 1969.

[3] Shur M.: Gallium Arsenide versus Silicon - Applications and Modeling. In: Snowden C.M. (eds) Semiconductor Device Modeling. Springer, London,1989.

[4] Winfried M.: Electronic properties of semiconductor interfaces. Springer-Verlag Berlin Heidelberg ,2004.

[5] Yoo, T.-W., and K. Chang.: Theoretical and Experimental Development of 10 and $35 \mathrm{GHz}$ Rectennas. IEEE Transactions on Microwave Theory and Techniques 40(6): 1259-1266.

[6]Baliga, B. Jayant, 2009.: Chapter 2 Advanced Power Rectifier Concepts. New York: Springer.

[7] Tyagi, M. S., 1977,: Surface States and Barrier Height at Metal-GaAs Interface. Japanese Journal of Applied Physics 16(S1): 333.

[8] Sachtler, W.M.H., G.J.H. Dorgelo, and A.A. Holscher, 1966.: The Work Function of Gold. Surface Science 5(2): 221-229.

[9] Seong-Jin Kim, 2006.: Breakdown Voltage Characteristics of SiCSchottky Barrier Diode with Aluminum Deposition Edge Termination Structure. Journal of the Korean Physical Society, Vol. 49, December 2006, pp. S768-S773.

[10] Hudait, M.K, and S.B Krupanidhi, 2001.: Doping Dependence of the Barrier Height and Ideality Factor of Au/n-GaAs Schottky Diodes at Low Temperatures .Physica B: Condensed Matter 307(1-4): 125-137.

[11] Christou, A., and W.M. Webb, 2006.: GaAs MMIC Reliability - High Temperature Behavior. Center for Risk and Reliability. https://books.google.co.ma/books?id=3jqGxfdr_04C.

[12] Shur, Michael, Sergey L. Rumyantsev, and M. E. Levinshteĭn, eds., 2006, Page 97.: SiC Materials and Devices. Selected Topics in Electronics and Systems, v. 40. New Jersey; London: World Scientific.

[13] Ou, Jun-hui, Shao Yong Zheng, Andrey S. Andrenko, Yuanxin Li, and Hong-Zhou Tan, 2018.: Novel Time-Domain Schottky Diode Modeling for Microwave Rectifier Designs . IEEE Transactions on Circuits and Systems I: Regular Papers 65(4): 1234-1244.

[14] Hakim Takhedmit, 2010.: Modélisation et conception de circuits de réception complexes pour la transmission d'énergie sans fil à $2.45 \mathrm{GHz}$.Autre. Ecole Centrale de Lyon, 2010

[15] Zbitou,J.,Latrach, M. and Toutain, S. 2006. : Hybrid rectenna and monolithic integrated zerobias microwave rectifier. IEEE Transactions on Microwave Theory and Techniques. 54, 1 (Jan.2006), $147-152$.

[16] Z. Harouni, L. Cirio, L. Osman, A. Gharsallah, and O. Picon, : A dual circularly polarized 2.45$\mathrm{GHz}$ rectenna for wireless powertransmission, IEEE Antennas Wireless Propag. Lett., vol. 10, pp. 306-309, 2011.

[17] Ladan, Shabnam \& Babu Guntupalli, Ajay \& Wu, Ke. (2014). : A High-Efficiency 24 GHz Rectenna Development Towards Millimeter-Wave Energy Harvesting and Wireless Power Transmission. Circuits and Systems I: Regular Papers, IEEE Transactions on. 61. 3358-3366. 10.1109/TCSI.2014.2338616. 